\title{
OBSERVATIONS ON THE PLASMA PROTHROMBIN AND THE EFFECTS OF VITAMIN $K$ IN PATIENTS WITH LIVER OR BILIARY TRACT DISEASE ${ }^{1}$
}

\author{
By FREDERICK J. POHLE AND JOHN K. STEWART \\ (From the Departments of Medicine and Clinical Pathology, University of Wisconsin Medical \\ School, Madison)
}

(Received for publication October 27, 1939)

There is general agreement that the newer methods for the quantitative determination of plasma prothrombin $(1,2,3,4)$ measure a deficiency that frequently occurs in jaundiced individuals. Numerous studies $(5,6,7,8,9)$ indicate that a reduction in prothrombin is responsible for the hemorrhagic diathesis which some of these patients exhibit. Some investigators (3, $8,10,11,12,13)$ conclude that the prothrombin deficiency, and the hemorrhagic state associated with it, can be corrected by the administration of preparations containing the fat-soluble antihemorrhagic vitamin $\mathrm{K}$, with bile salts.

The use of vitamin $\mathrm{K}$ in the treatment of the bleeding tendency in obstructive jaundice was first proposed on theoretical grounds by Quick (14). Actual clinical trial of this therapy was begun independently shortly afterwards by Warner, Brinkhous and Smith (2), Butt, Snell and Osterberg (15), and Dam and Glavind (16). These reports and subsequent studies have been extremely enthusiastic regarding the value of crude concentrates of vitamin $\mathrm{K}$ administered with bile salts in restoring the prothrombin to normal and in controlling hemorrhage in jaundiced individuals. Very few failures have been reported (13). The purpose of the present investigation was to study critically the efficacy of this new therapy in a large series of consecutive cases of liver or biliary tract disease.

\section{METHODS}

Prothrombin determination. The plasma prothrombin was measured quantitatively by a modified Quick method which has been described elsewhere (9). The prothrombin time was determined on $0.1 \mathrm{cc}$. portions of oxalated plasma in clean dry 100 by $13 \mathrm{~mm}$. test tubes in a water bath at $37.5^{\circ} \mathrm{C}$. No plasma showing gross lipemia was used. An excess of thromboplastin was supplied by the

1 This study was aided in part by a grant from the Wisconsin Alumni Research Foundation. addition of 0.1 cc. of a freshly prepared saline suspension of acetone dehydrated rabbit brain. One-tenth cc. of an optimal calcium chloride solution (9) was added with a blow pipette, and the time required for coagulation after the addition of calcium was observed with a stop watch. With optimal recalcification the normal prothrombin time was 10 seconds (equivalent to 100 per cent). The prothrombin time was converted to the percentage concentration of plasma prothrombin with the aid of a graph previously described (9). The prothrombin was determined on normal plasma on each occasion to assure proper activity of the thromboplastin and the absence of calcium contamination of the glassware. All prothrombin determinations were done by the authors. In most cases the test was performed three times per week, but in many instances it was done daily.

$V$ itamin $K$. The source of vitamin $\mathrm{K}$ used in a majority of the present observations was a preparation of dried young cereal plants (oats and wheat) in powder form, marketed under the name of Cerophyl.2 A single allotment was used throughout the present studies. It was stored away from light in an ice box kept at $4^{\circ} \mathrm{C}$. Elvehjem (17) assayed this material at 3-month intervals and found on each occasion that it protected chicks from hemorrhagic manifestations when added to a vitamin $\mathrm{K}$-free diet in the proportion of $1: 400$. Cerophyl contains other vitamins, namely, carotene, thiamine, ascorbic acid and riboflavin. With the possible exception of carotene, these are present in such small amounts that it is unlikely that they would have significant effects.

The powdered preparation was mixed with milk, fruit juice or tomato juice and the suspension administered three times daily with meals. The total daily dose varied with the individual patient from 27 to $54 \mathrm{cc}$. These amounts were equivalent to from 12 to 24 grams. Concomitantly, from 2 to 4 grams of animal bile salts were always given to aid in the absorption of the fat-soluble vitamin (18). The bile salt preparation used was Bilron ${ }^{3}$ which was administered in $\mathbf{5}$ grain capsules. Experience in this clinic indicates that these dosages are greater than the minimal requirements for the control of the hemorrhagic diathesis in the usual case with obstructive jaundice.

In a few instances preparations of vitamin $\mathrm{K}$ other than powdered Cerophyl were employed. Five cases were

2 The Cerophyl employed was generously supplied by the Cerophyl Laboratories, Kansas City, Mo.

$s$ Eli Lilly and Company, Indianapolis, Ind. 
treated with 3 grams of a hexane extract of Cerophyl daily. This concentrate was sixteen times more potent by weight than the original material (17). Three patients were treated with 1.6 grams of a commercial alfalfa concentrate 4 daily.

The vitamin $\mathrm{K}$ preparation and bile salts were administered orally to all subjects. Occasionally the medication was not well tolerated and caused nausea and vomiting. The patients were closely observed and if the medication was not retained it was repeated. In such individuals it was sometimes necessary to give the medication through a duodenal tube. In some patients, who could take nothing by mouth for several days after operation, continuation of the therapy was achieved by administration of the material through a duodenal tube which was inserted at the time of surgery.

Material studied. One hundred and thirty-six consecutive patients with liver or biliary tract disease were studied. All of the patients were adults except for 3 infants. Each patient was hospitalized during the period of observation. The diet in most instances was characterized by its low fat and high carbohydrate content. One hundred and five individuals in this group had various types of abdominal surgery performed.

The diagnosis was definitely established in the majority of these patients by histopathological studies. In 15 cases biopsy of the liver was done at the time of an exploratory operation. Complete autopsy was performed on 8 of the 10 cases who died. The icterus index, quantitative urobilinogen studies on the urine, stool examinations and blood studies were done routinely. The serum albumin and globulin were determined in all cases where hepatic damage was suspected. Additionally, the galactose tolerance test, hippuric acid test (19), and the cephalin-cholesterol test (20) were frequently employed.

\section{RESULTS}

Incidence of a reduction of prothrombin. The percentage concentration of plasma prothrombin was reduced below 100 in 64 cases, or 47 per cent of the 136 patients with liver or biliary tract disease studied. The remaining 72 patients had a normal plasma prothrombin on repeated determinations. There was no correlation between the intensity or duration of jaundice and the prothrombin value. Table I shows the number of patients with normal and reduced prothrombin in relation to the primary diagnosis.

Analysis of patients with normal prothrombin. None of the 72 individuals in whom a normal plasma prothrombin was repeatedly demonstrated showed evidence of a hemorrhagic diathesis. Forty-eight of these cases had abdominal surgery performed. Of this group, 20 patients received
TABLE I

Incidence of a reduction of prothrombin in 136 cases of liver or biliary tract disease

\begin{tabular}{|c|c|c|c|}
\hline Diagnosis & $\begin{array}{l}\text { Total } \\
\text { num - } \\
\text { ber } \\
\text { of } \\
\text { cases }\end{array}$ & $\begin{array}{c}\text { Number } \\
\text { of } \\
\text { cases } \\
\text { vith } \\
\text { reduced } \\
\text { pro- } \\
\text { thrombin }\end{array}$ & $\begin{array}{c}\text { Number } \\
\text { of } \\
\text { cases } \\
\text { with } \\
\text { normal } \\
\text { pro- } \\
\text { thrombin }\end{array}$ \\
\hline 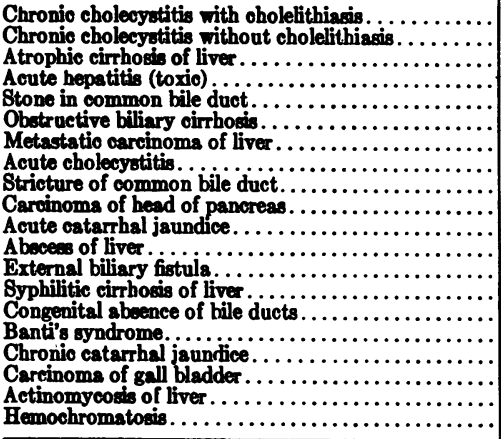 & \begin{tabular}{r|}
35 \\
19 \\
12 \\
9 \\
7 \\
6 \\
6 \\
6 \\
6 \\
5 \\
6 \\
5 \\
3 \\
3 \\
3 \\
3 \\
3 \\
3 \\
2 \\
1 \\
1 \\
1 \\
1
\end{tabular} & $\begin{array}{l}7 \\
1 \\
9 \\
9 \\
7 \\
6 \\
6 \\
3 \\
3 \\
0 \\
4 \\
5 \\
1 \\
1 \\
2 \\
3 \\
3 \\
3 \\
3 \\
1 \\
0 \\
1 \\
1 \\
1 \\
1\end{array}$ & $\begin{array}{r}28 \\
18 \\
3 \\
2 \\
1 \\
0 \\
3 \\
6 \\
1 \\
1 \\
4 \\
1 \\
0 \\
0 \\
0 \\
2 \\
2 \\
0 \\
0 \\
0\end{array}$ \\
\hline Totals. & 136 & 64 & 72 \\
\hline
\end{tabular}

vitamin $\mathrm{K}$ and bile salts both before and after operation, while the remainder were untreated. No difference was observed in the course of the treated and untreated group. Three of this group of 72 patients died from causes unrelated to their biliary tract disease.

The remainder of this communication will be limited to a report of the observations on the 64 patients who presented a reduction in plasma prothrombin.

Analysis of patients with reduced prothrombin who were treated. Forty-six patients of the group of 64 with reduced plasma prothrombin were adequately treated with vitamin $\mathrm{K}$ and bile salts. The remainder of this group were selected as controls and received no treatment.

The effects of vitamin $K$ and bile salt therapy on the prothrombin values in the 46 individuals with a deficiency of this coagulation factor were not uniform. Twenty-eight cases showed an increase of the prothrombin to normal or approximately normal values. Table II gives the diagnosis, prothrombin percentage before and after treatment, and the number of days of therapy required to produce the satisfactory response in these cases. The rate of prothrombin formation was quite variable. In most instances the increase in prothrombin was characterized by a regular progression in the percentage concentration. Al- 
TABLE II

Effect of vitamin $K$ and bile salts on the plasma prothrombin in 28 jaundiced patients with reduced prothrombin

\begin{tabular}{|c|c|c|c|}
\hline Diagnosis & $\begin{array}{l}\text { Pro- } \\
\text { throm- } \\
\text { bin } \\
\text { before } \\
\text { treat- } \\
\text { ment }\end{array}$ & $\begin{array}{l}\text { Pro- } \\
\text { throm- } \\
\text { bin } \\
\text { after } \\
\text { treat- } \\
\text { ment }\end{array}$ & $\begin{array}{l}\text { Time } \\
\text { required } \\
\text { for } \\
\text { pro- } \\
\text { throm- } \\
\text { bin re- } \\
\text { sponses }\end{array}$ \\
\hline 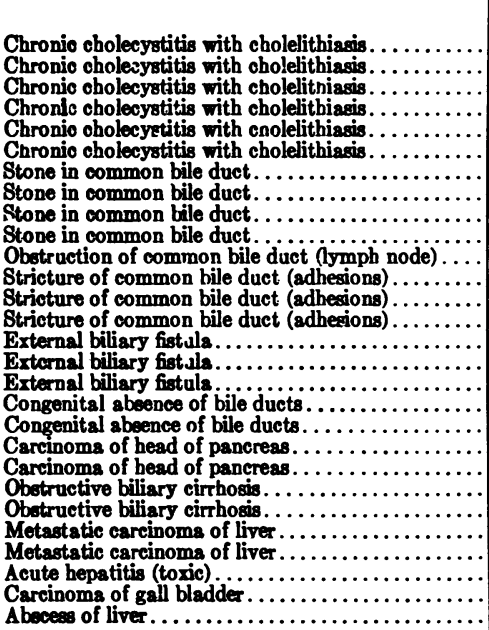 & $\begin{array}{c}\text { per cent } \\
65 \\
70 \\
65 \\
60 \\
50 \\
35 \\
25 \\
50 \\
30 \\
60 \\
35 \\
30^{*} \\
5 \\
30 \\
18 \\
20 \\
18 \\
15 \\
22 \\
17 \\
20 \\
45 \\
28 \\
28 \\
30 \\
45 \\
17 \\
40\end{array}$ & $\begin{array}{c}\text { per cent } \\
100 \\
100 \\
100 \\
100 \\
100 \\
80 \\
100 \\
100 \\
100 \\
100 \\
100 \\
100 \\
70 \\
100 \\
50 \\
100 \\
100 \\
100 \\
100 \\
100 \\
80 \\
100 \\
100 \\
100 \\
80 \\
100 \\
70 \\
80\end{array}$ & $\begin{array}{r}\text { days } \\
9 \\
6 \\
4 \\
9 \\
7 \\
5 \\
6 \\
3 \\
5 \\
3 \\
6 \\
6 \\
16 \\
11 \\
5 \\
5 \\
15 \\
5 \\
4 \\
3 \\
7 \\
7 \\
17 \\
6 \\
6 \\
10 \\
2 \\
10\end{array}$ \\
\hline
\end{tabular}

* Hemorrhage.

though an increase was usually observed within 24 hours after treatment was started, the normal value was ordinarily not attained until several days later. These findings are similar to those recently reported by Smith, Ziffren, Owen and Hoffman (21) and are less dramatic than the prompt responses reported in the early literature. Figure 1 shows the rise in prothrombin which

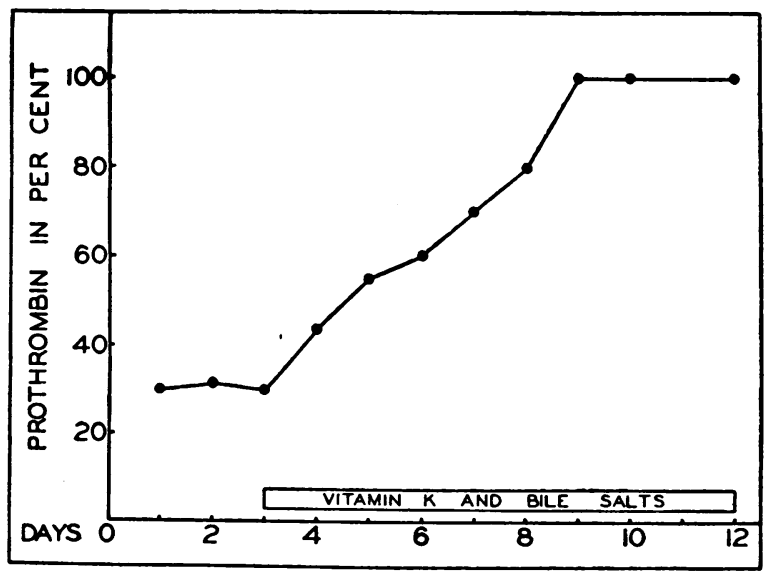

Fig. 1. Effect of the Oral Administration of Vitamin K and Bile Salts on the Plasma Prothrombin in a Patient with Obstructive Jaundice

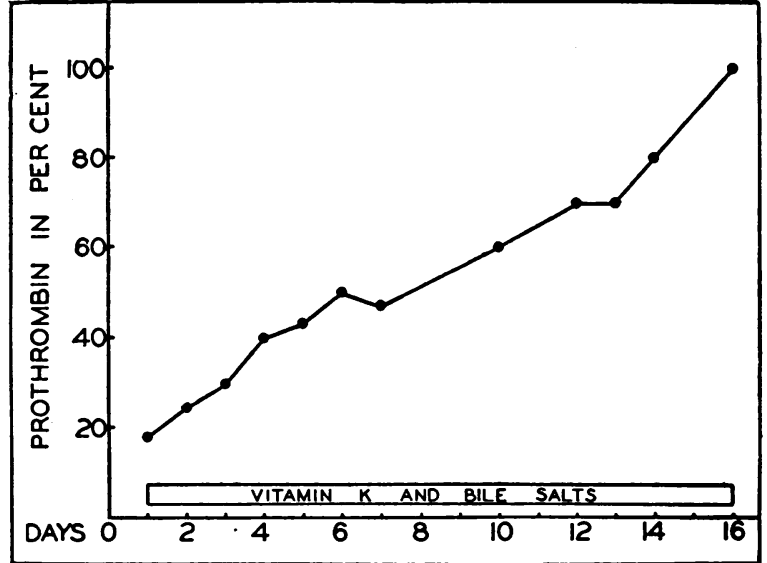

Fig. 2. Effect of the Oral Administration of Vitamin K and Bile Salts on the Plasma Prothrombin in a Patient with a Chronic External Biliary Fistula

followed the administration of vitamin $\mathrm{K}$ and bile salts to an individual with obstructive jaundice due to stones in the common bile duct. Figure 2 shows the improvement in prothrombin which followed similar therapy in a patient with an external biliary fistula of one and a half years' duration. Figure 3 presents data from an indi-

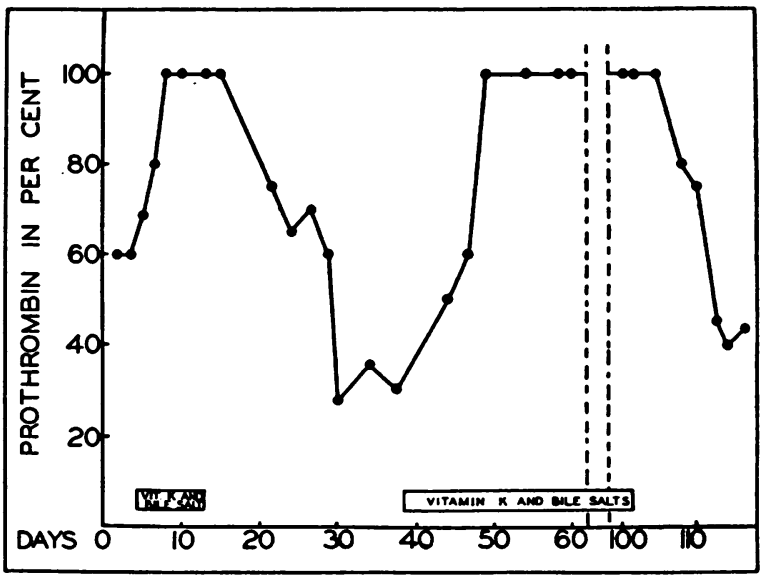

Fig. 3. Effect of the Oral Administration of Vitamin K and Bile Salts and Their Withdrawal on the Plasma Prothrombin in a Patient with ObSTRUCTIVE JAUNDICE

vidual with long-standing obstructive jaundice due to adhesions about the common bile duct. This figure clearly shows the return of the prothrombin to normal on two occasions coincident with treatment and the fall to subnormal levels following withdrawal of therapy. Such data furnish strong 
TABLE III

Lack of effect of vitamin $K$ and bile salts on the plasma prothrombin in 18 patients with reduced prothrombin

\begin{tabular}{|c|c|c|c|}
\hline Diagnosis & $\begin{array}{c}\text { Pro- } \\
\text { throm- } \\
\text { bin } \\
\text { before } \\
\text { treat- } \\
\text { ment }\end{array}$ & $\begin{array}{c}\text { Pro- } \\
\text { throm- } \\
\text { bin } \\
\text { after } \\
\text { treat- } \\
\text { ment }\end{array}$ & $\begin{array}{c}\text { Dura- } \\
\text { tion } \\
\text { of } \\
\text { treat- } \\
\text { ment }\end{array}$ \\
\hline & $\begin{array}{l}\text { per } \\
\text { cent }\end{array}$ & $\begin{array}{l}\text { per } \\
\text { cent }\end{array}$ & days \\
\hline Atrophic cirrhosis of liver. & 55 & 40 & 27 \\
\hline Atrophic cirrhosis of liver. & 70 & 50 & 24 \\
\hline Atrophic cirrhosis of liver. & 60 & 60 & 14 \\
\hline Atrophic cirrhosis of liver. & 50 & 50 & 9 \\
\hline Atrophic cirrhosis of liver. & 28 & $12 *$ & 21 \\
\hline Atrophic cirrhosis of liver. & 47 & 50 & 14 \\
\hline Atrophic cirrhosis of liver. & 45 & 35 & 16 \\
\hline Obstructive biliary cirrhosis & 45 & $9^{*}$ & 15 \\
\hline Obstructive biliary cirrhosis. & 40 & $15^{*}$ & 17 \\
\hline Obstructive biliary cirrhosis. & 30 & $5^{*}$ & 18 \\
\hline Stone in common bile duct . & 20 & 30 & 8 \\
\hline Stone in common bile duct . & 80 & $20^{*}$ & 12 \\
\hline rinoma of head of mancrea & 40 & 32 & 25 \\
\hline cinoma of head of pancreas & 80 & $10^{*}$ & 14 \\
\hline Multiple abscesses of liver & 70 & $22^{*}$ & 22 \\
\hline etastatic carcinoma of liver & 32 & 40 & 15 \\
\hline ngenital absence of bile duct & 50 & 50 & 25 \\
\hline philitic cirrhosis of liver. & 70 & 70 & 15 \\
\hline
\end{tabular}

* Hemorrhage.

evidence that the vitamin $\mathrm{K}$ and bile salts were in some way responsible for the improvement noted.

Eighteen of the 46 patients with a prothrombin deficiency who were treated showed no significant increase in prothrombin and thus may be classed as failures. Table III gives the diagnosis, prothrombin percentage before and after treatment and the number of days that the therapy was administered in these cases. These data show that not only was there no increase of prothrombin, but in some instances the treatment was accompanied by an actual reduction. Comparison of Tables II and III shows that the duration of therapy was greater in the group of 18 failures than in the group of 28 successes. In the 18 cases where there was no increase of prothrombin with treatment, the dosage of vitamin $K$ and bile salts was often larger than in the group with good responses. If there was no improvement in the prothrombin value after several days of treatment the dosage was usually doubled. Figure 4 shows the failure of response of the prothrombin to treatment in a case with advanced atrophic cirrhosis of the liver. This figure is typical of the data obtained on the other patients with atrophic cirrhosis of the liver. In 5 surgical

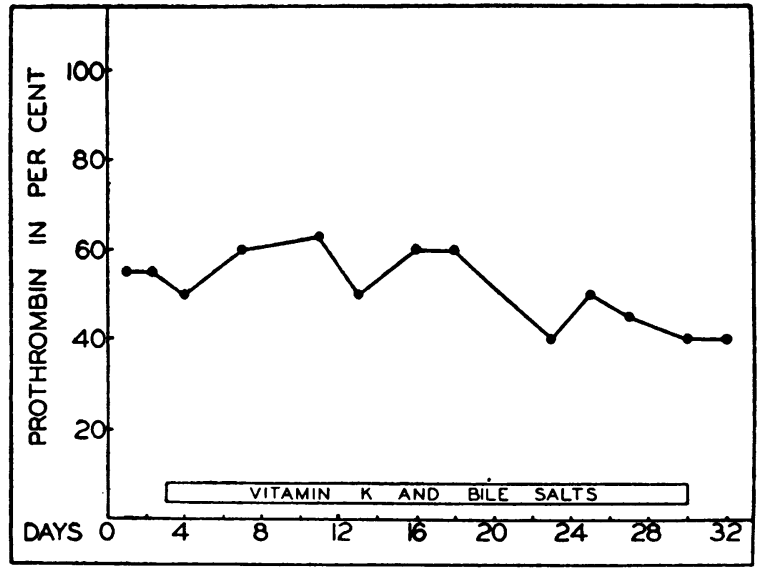

Fig. 4. Lack of Effect of the Oral Administration of Vitamin $K$ and Bile Salts on the Plasma Prothrombin in a Patient with Advanced Atrophic Cirrhosis of The Liver

cases, the therapeutic failure occurred during the postoperative period. In each of these 5 patients the prothrombin decreased to a low level and hemorrhage occurred in spite of the continuation of therapy. Figure 5 gives the data on these patients.

Analysis of patients with reduced prothrombin who were not treated. Eighteen patients of the group of 64 with reduced plasma prothrombin served as controls and received no vitamin $K$ or bile salts. In no case was the period of observation less than 12 days. Eleven of these patients, 7 of whom underwent surgery, showed no significant change in their prothrombin value. One other untreated patient showed a return of the prothrombin to normal following surgical relief of obstruction to the common bile duct (Figure $6)$. The one fatality in this group was an individual with obstructive jaundice due to a carcinoma of the pancreas in whom the prothrombin was persistently below 25 per cent. This patient became comatose and died after 12 days of observation. Two large subdural hematomata were found at autopsy. The remaining 5 untreated patients suffered from an acute toxic hepatitis. All showed a progressive reduction in prothrombin as the severity of the disease increased. This was followed by a gradual return of the prothrombin to normal with recovery from the hepatitis. Figure 7 presents data on one of these cases in whom the hepatitis followed a hysterectomy under 

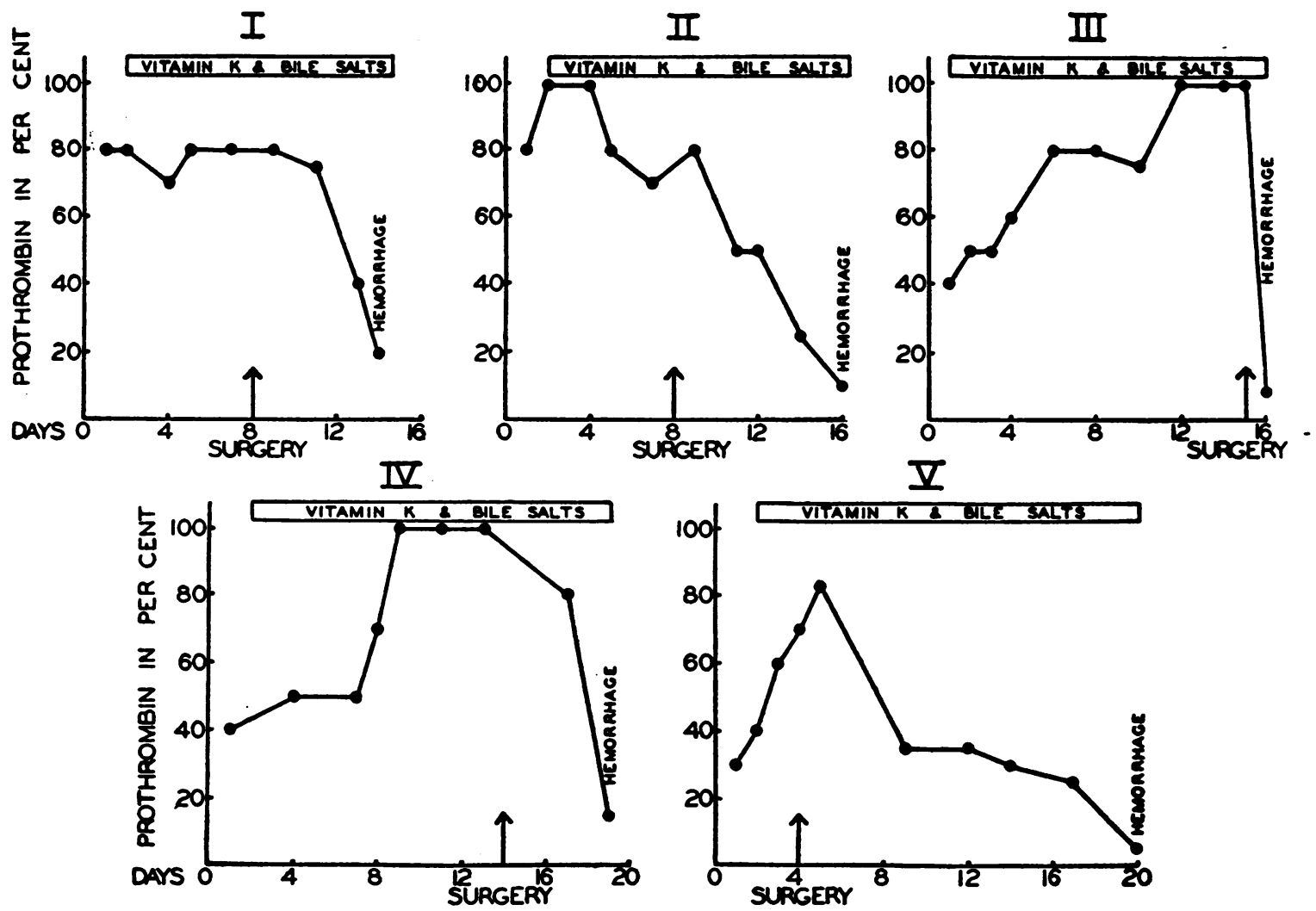

Fig. 5. Postoperative Decrease in Plasma Prothrombin, with Hemorrhage, in 5 Patients with Obstructive Biliaky Cirrhosis

inhalation anesthesia. The changes in the prothrombin and icterus index shown in Figure 7 are typical of those observed in the other patients with acute hepatitis.

Analysis of patients who bled. Ten of the 64

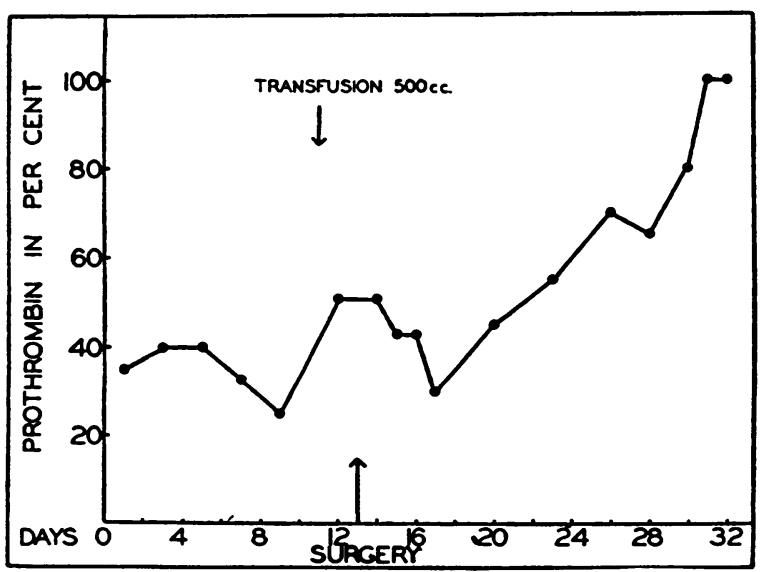

Fig. 6. Changes in the Plasma Prothrombin following Surgical Relief of Obstruction to the ComMON Bile Duct patients with a reduction of prothrombin had definite abnormal bleeding. Seven of these 10 patients died as a result of hemorrhage. The data in Table IV show that the bleeding tendency in each case was associated with a marked de-

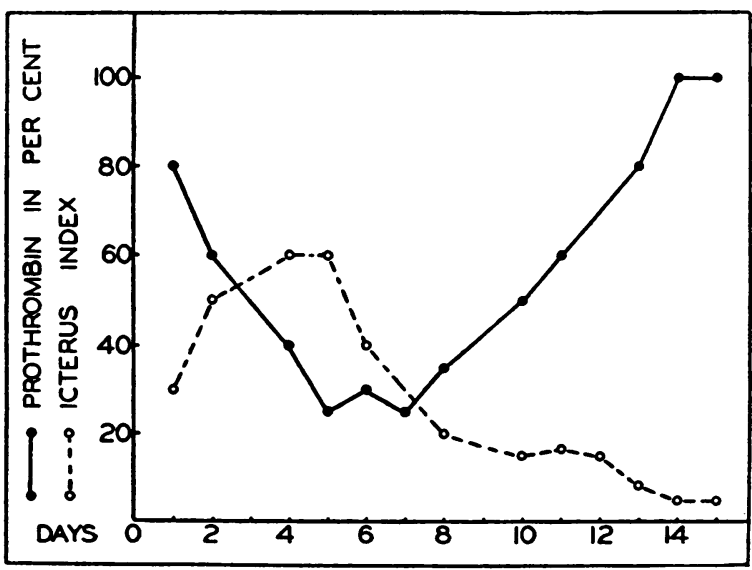

Fig. 7. Changes in the Plasma Prothrombin and Icterus Index During the Course of an Acute Toxic Hepatitis 
TABLE IV

Prothrombin values and clinical notes on 10 jaundiced patients who bled

\begin{tabular}{|c|c|c|c|}
\hline Diagnosis & $\begin{array}{l}\text { Adequate } \\
\text { vitamin K } \\
\text { and } \\
\text { bile } \\
\text { salts } \\
\text { prior to } \\
\text { Lemorrhage }\end{array}$ & $\begin{array}{l}\text { Pro- } \\
\text { throm- } \\
\text { bin at } \\
\text { time } \\
\text { of } \\
\text { hemor- } \\
\text { rhage }\end{array}$ & Clinical notes \\
\hline $\begin{array}{l}\text { Stones in common bile duct } \\
\text { with obstructive biliary cir- } \\
\text { rhosis (Case I, Figure 5) }\end{array}$ & Yes & $\begin{array}{c}\text { per cont } \\
20\end{array}$ & $\begin{array}{l}\text { Massive intra-abdominal } \\
\text { hemorrhage on 6th postop- } \\
\text { erative day. Evisceration. } \\
\text { Death. Autopey. }\end{array}$ \\
\hline $\begin{array}{l}\text { Carcinoma of head of pan- } \\
\text { creas with obstructive bili- } \\
\text { ary cirrhosis (Case II, } \\
\text { Figure 5) }\end{array}$ & Yes & 10 & $\begin{array}{l}\text { Massive intra-abdominal } \\
\text { hemorrhage on 8th post- } \\
\text { operative day. Death. } \\
\text { Autopey. }\end{array}$ \\
\hline $\begin{array}{l}\text { Advanced obstructive bili- } \\
\text { ary cirrhosis (Case III, } \\
\text { Figure 5) }\end{array}$ & Yes & 9 & $\begin{array}{l}\text { Massive intra-abdominal } \\
\text { hemorrhage on 1st post- } \\
\text { operative day. Death. } \\
\text { Autopay. }\end{array}$ \\
\hline $\begin{array}{l}\text { Advanced obstructive bili- } \\
\text { ary cirrhosis (Case IV, } \\
\text { Figure 5) }\end{array}$ & Yes & 15 & $\begin{array}{l}\text { Intra-abdominal hemor- } \\
\text { rhage on 4th postoperative } \\
\text { day. Death. Autopey. }\end{array}$ \\
\hline $\begin{array}{l}\text { Advanced obstructive bili- } \\
\text { ary cirrhosis (Case V, } \\
\text { Figure 5) }\end{array}$ & Yes & 5 & $\begin{array}{l}\text { Hemorrhage into abdominal } \\
\text { cavity on 16th postopera- } \\
\text { tive day. }\end{array}$ \\
\hline $\begin{array}{l}\text { Obatructive jaundice due to } \\
\text { carcinoma of head of pan- } \\
\text { oreas }\end{array}$ & No & 16 & $\begin{array}{l}\text { Two large subdural hemato- } \\
\text { mats following alight head } \\
\text { injury. Death. Autopey. }\end{array}$ \\
\hline $\begin{array}{l}\text { Atrophic cirrhosis of liver } \\
\text { with subscute hepatitis }\end{array}$ & Yes & 12 & $\begin{array}{l}\text { Bleeding from abdominal } \\
\text { paracentesis wound and } \\
\text { from gastrointestinal tract. } \\
\text { Death. Autopey. }\end{array}$ \\
\hline $\begin{array}{l}\text { Obatructive jaundice due to } \\
\text { adhecions about common } \\
\text { bile duet }\end{array}$ & No & 30 & Bleeding from the gums. \\
\hline $\begin{array}{l}\text { Advanced obstructive bili- } \\
\text { ary cirrhosis }\end{array}$ & No & 28 & $\begin{array}{l}\text { Epistaxis. Severe bleeding } \\
\text { from the gums. }\end{array}$ \\
\hline Multiple abscesses of liver & Yes & 22 & $\begin{array}{l}\text { Intra-abdominal hemor- } \\
\text { rhage. Death. Autopay. }\end{array}$ \\
\hline
\end{tabular}

crease in the plasma prothrombin. This table also shows that the hemorrhage occurred in 7 of the 10 cases in spite of the administration of vitamin $\mathrm{K}$ and bile salts. One other patient, with a prothrombin of 60 per cent, bled from the abdominal wound during the second and third postoperative days. This case was not included in Table IV since exploration of the incision revealed the source of hemorrhage to be a single unligated vessel. In this case the cause of bleeding was interpreted as mechanical rather than being due to a coagulation defect from prothrombin deficiency.

\section{DISCUSSION}

There is general agreement that normal human plasma contains an excess of prothrombin which under healthy conditions shows only slight fluctuations. A decrease in prothrombin occurs prin- cipally in jaundiced individuals. Quick (7), however, states that relatively few jaundiced patients exhibit such a deficiency. In 136 cases with liver or biliary tract disease observed in the present investigation, a reduction in the prothrombin was demonstrated in 64 (47 per cent). This figure coincides rather closely with the incidence of 40 per cent in 43 patients with obstructive jaundice reported by Rhoads (13).

The present observations confirm previous studies which indicate that the prothrombin determination is a satisfactory test for the detection of a hemorrhagic diathesis in jaundiced individuals. The need for such a prognostic test is obvious since current figures (8) indicate that cholemic bleeding has accounted for about 50 per cent of the mortality accompanying surgical intervention in jaundiced patients. In the present series of 136 cases having jaundice, 10 showed abnormal bleeding. Each of these 10 cases with hemorrhage had a prothrombin of 30 per cent or below. Fifteen other cases with this degree of prothrombin deficiency showed no hemorrhagic tendency. The establishment of a "critical level" of prothrombin below which cholemic bleeding may be anticipated is dangerous because of the false sense of security it may give in the evaluation of certain borderline cases. These data suggest, however, that any patient with a prothrombin concentration of 30 per cent or below should be considered a potential bleeder.

Vitamin $\mathrm{K}$ and bile salts have been used in the treatment and prevention of cholemic bleeding because of the beneficial effect on prothrombin formation. Many of the clinical reports have been presented with enthusiasm and, in general, received with optimism. Few cases have been recorded in which this new therapy has failed to restore the prothrombin to normal (13). The present studies clearly show that in the majority of jaundiced patients with prothrombin deficiency the administration of vitamin $\mathrm{K}$ with bile salts corrects the defect in this coagulation factor. These studies also show, however, that there is a lack of a favorable response in a significant number of cases. The 18 failures noted in this investigation cannot be ignored.

The explanation for the failure of the prothrombin to respond to treatment in 18 patients seems to be of special interest. Inaccuracies in the 
quantitative determination of prothrombin cannot be blamed because the results were not evaluated entirely by this criterion. In 7 of these patients (Table III) persistence of a low level of prothrombin was accompanied by alarming and sometimes fatal hemorrhage. The dosage of vitamin $\mathrm{K}$ and bile salts appeared to be adequate since the amount and duration of therapy were greater in the 18 failures than in the 28 patients who responded satisfactorily. The administration of larger amounts of the crude preparation of vitamin $\mathrm{K}$ was not practical. The data in Tables II and III and the other laboratory studies on these 46 patients suggest that the essential difference between the therapeutic successes and failures was the state of the liver function. The group of 18 so-called failures was composed of patients in whom liver function tests or histopathological studies, or both, revealed extensive damage to the liver parenchyma. Similar studies showed no indication that hepatic damage of this degree was present in the group of 28 patients who responded satisfactorily. Relatively little attention has been paid to the functional integrity of the liver in evaluation of the prothrombin response to vitamin $K$ and bile salt therapy. Warner (22) and Butt, Snell and Osterberg (8) have encountered an occasional patient with severe hepatic damage who did not present the usual prompt improvement of prothrombin following the administration of vitamin $K$ and bile salts. The present studies indicate that vitamin $K$ and bile salts are commonly ineffective in correcting a prothrombin deficiency if extensive hepatic damage is present.

Recent experiments indicate that the liver is the site of formation of prothrombin $(2,23,24,25)$. The observations on the prothrombin fluctuations during acute hepatitis (Figure 7) add further support, of a clinical nature, to this conclusion. These data also suggest that in the absence of biliary obstruction, external biliary fistula, or an abnormal intestinal absorptive surface, the plasma prothrombin concentration is a measure of liver function.

Studies by Butt, Snell and Osterberg (8) and others have shown that a decrease in prothrombin is not uncommon after operations on jaundiced individuals. Stewart (26) observed that an aver- age postoperative decrease in prothrombin of 23 per cent occurred in 19 cases with obstructive jaundice. Butt, Snell and Osterberg have emphasized the necessity for continued administration of vitamin $\mathrm{K}$ and bile salts, as well as other treatment known to be of value in the restoration of normal hepatic function, during the postoperative period. The present observations also show that a decrease of prothrombin is not uncommon after surgery and suggest that this drop is especially likely to occur if significant hepatic damage is present.

The mechanism by which vitamin $K$ affects prothrombin has not been fully explained. It has been presumed that vitamin $\mathrm{K}$ is a necessary building stone for the formation of prothrombin. It has not, however, been proven that vitamin $\mathrm{K}$ is essential in the diet of human beings. The nature and mode of action of prothrombin are not known. Patek and Taylor (27) have described it as a physiologic complex known only by its capacity to form thrombin. The mode of action of vitamin $\mathrm{K}$ will not be fully understood until further studies are made with the purer preparations of the vitamin now available, and until more is learned about the nature of prothrombin and the part it plays in blood coagulation.

\section{CONCLUSIONS}

1. In 136 consecutive cases of liver or biliary tract disease the incidence of a reduction in plasma prothrombin below normal was 47 per cent. Intrinsic liver disease was a frequent cause of the prothrombin deficiency.

2. A marked reduction of the plasma prothrombin was present in each of 10 individuals who exhibited abnormal bleeding. The data suggest that hemorrhage should be anticipated when the prothrombin concentration is 30 per cent or below.

3. The effect of the oral administration of vitamin $K$ and bile salts on the prothrombin in 46 jaundiced patients with a reduction in this coagulation factor was not uniform. Twenty-eight patients showed a satisfactory increase in prothrombin while 18 patients showed no improvement.

4. The failure of vitamin $K$ and bile salts to produce an increase in the prothrombin in certain 
cases with jaundice is often due to the presence of extensive hepatic damage.

5. The decrease in prothrombin which is not uncommon after surgical intervention in jaundiced patients is especially likely to occur if hepatic damage is present.

6. The present studies suggest that in the absence of obstructive jaundice, external biliary fistula, or an abnormal intestinal absorptive surface, the plasma prothrombin concentration serves as a measure of liver function.

The authors gratefully acknowledge the assistance of Professor C. A. Elvehjem, and the ready cooperation of Dr. E. R. Schmidt and the members of his staff in the Department of Surgery.

\section{BIBLIOGRAPHY}

1. Quick, A. J., Prothrombin in hemophilia and in obstructive jaundice. J. Biol. Chem., 1935, 109, lxxiii.

2. Warner, E. D., Brinkhous, K. M., and Smith, H. P., Quantitative study on blood clotting: prothrombin fluctuations under experimental conditions. Am. J. Physiol., 1936, 114, 667.

3. Dam, H., and Glavind, J., The clotting power of human and mammalian blood in relation to vitamin K. Acta med. Scandinav., 1938, 96, 108.

4. Ziffren, S. E., Owen, C. A., Hoffman, G. R., and Smith, H. P., Control of vitamin K therapy. Compensatory mechanisms at low prothrombin levels. Proc. Soc. Exper. Biol. and Med., 1939, 40, 595.

5. Brinkhous, K. M., Smith, H. P., and Warner, E. D., Prothrombin deficiency and the bleeding tendency in obstructive jaundice and in biliary fistula; effect of feeding bile and alfalfa (Vitamin $\mathrm{K}$ ). Am. J. Med. Sc., 1938, 196, 50.

6. Dam, H., and Glavind, J., Determination of vitamin $\mathrm{K}$ by curative blood-clotting method. Biochem. J., 1938, 32, 1018.

7. Quick, A. J., The nature of the bleeding in jaundice. J. A. M. A., 1938, 110, 1658.

8. Butt, H. R., Snell, A. M., and Osterberg, A. E., The preoperative and postoperative administration of vitamin $\mathrm{K}$ to patients having jaundice. J. A. M. A., 1939, 113, 383.

9. Pohle, F. J., and Stewart, J. K., A study of the Quick method for the quantitative determination of prothrombin with suggested modifications. Am. J. Med. Sc., 1939, 198, 622.

10. Warner, E. D., Brinkhous, K. M., and Smith, H. P., Bleeding tendency of obstructive jaundice; prothrombin deficiency and dietary factors. Proc. Soc. Exp. Biol. and Med., 1938, 37, 628.

11. Olson, P. F., The prothrombin test and the vitamin
$\mathrm{K}$ treatment for the bleeding tendency in the jaundiced patient. J. Iowa M. Soc., 1939, 29, 103.

12. Stewart, J. D., Prothrombin deficiency and the effects of vitamin $\mathrm{K}$ in obstructive jaundice and biliary fistula. Ann. Surg., 1939, 109, 588.

13. Rhoads, J. E., The relation of vitamin $K$ to the hemorrhagic tendency in obstructive jaundice, with a report on Cerophyl as a source of vitamin $\mathrm{K}$. Surgery, 1939, 5, 794.

14. Quick, A. J., The coagulation defect in sweet clover disease and in the hemorrhagic chick disease of dietary origin. Am. J. Physiol., 1937, 118, 260.

15. Butt, H. R., Snell, A. M., and Osterberg, A. E., The use of vitamin $\mathrm{K}$ and bile in treatment of the hemorrhagic diathesis in cases of jaundice. Proc. Staff Meet., Mayo Clinic, 1938, 13, 74.

16. Dam, H., and Glavind, J., Vitamin $K$ in human pathology. Lancet, 1938, 1, 720.

17. Elvehjem, C. A., Personal communication.

18. Greaves, J. D., and Schmidt, C. L. A., Nature of the factor concerned in loss of blood coagulability of bile fistula rats. Proc. Soc. Exp. Biol. and Med., 1937, 37, 43.

19. Quick, A. J., The synthesis of hippuric acid; a new test of liver function. Am. J. Med. Sc., 1933, 185, 630.

20. Hanger, F. M., Serological differentiation of obstructive from hepatogenous jaundice by flocculation of cephalin-cholesterol emulsions. J. Clin. Invest., 1939, 18, 261.

21. Smith, H. P., Ziffren, S. E., Owen, C. A., and Hoffman, G. R., Clinical and experimental studies on vitamin K. J. A. M. A., 1939, 113, 380.

22. Warner, E. D., in discussion on Butt, H. R., Snell, A. M., and Osterberg, A. E. Oral and intramuscular administration of vitamin $\mathrm{K}$ in hemorrhagic diathesis of obstructive jaundice. J. A. M. A. (Society Proc. Abstr.), 1939, 112, 879.

23. Smith, H. P., Warner, E. D., and Brinkhous, K. M., Prothrombin deficiency and the bleeding tendency in liver injury (chloroform intoxication). J. Exper. Med., 1937, 66, 801.

24. Warner, E. D., Plasma prothrombin; effect of partial hepatectomy. J. Exper. Med., 1938, 68, 831.

25. Warren, R., and Rhoads, J. E., The hepatic origin of the plasma-prothrombin observations after total hepatectomy in the dog. Am. J. Med. Sc., 1939, 198, 193.

26. Stewart, J. D., in discussion on Butt, H. R., Snell, A. M., and Osterberg, A. E., The preoperative and postoperative administration of vitamin $\mathrm{K}$ to patients having jaundice. J. A. M. A., 1939, 113, 383.

27. Patek, A. J., Jr., and Taylor, F. H. L., Hemophilia. II. Some properties of a substance obtained from normal human plasma effective in accelerating the coagulation of hemophilic blood. J. Clin. Invest., 1937, 16, 113. 